\title{
Comparison of Physiological Responses to Maximal Arm Exercise Among Able-bodied, Paraplegics and Quadriplegics
}

\author{
Marta D. Van Loan, Ph.D., ${ }^{1}$ Shirley McCluer, M.D., ${ }^{2}$ J. Mark Loftin, \\ Ph.D. ${ }^{3}$ and R. A. Boileau, Ph.D. ${ }^{4}$ \\ ${ }^{1}$ U.S. Department of Agriculture, Western Human Nutrition Research Center, \\ Presidio of San Francisco, California 94129, '2 Division of Rehabilitation Medicine; \\ University of Arkansas for Medical Science, Little Rock, Arkansas 72205, \\ ${ }^{3}$ Department of Health and Physical Education, University of New Orleans, \\ Louisiana 70148, ${ }^{4}$ Physical Fitness Research Laboratory, Department of Physical \\ Education, University of Illinois, Urbana, Illinois 61820, U.S.A.
}

\section{Summary}

A comparison of pulmonary, cardiovascular and metabolic responses was made in 32 subjects consisting of 11 able-bodied, 8 paraplegics (T4-L3 lesions) and 13 quadriplegics (C5-C8 lesions) during maximal arm cranking exercise. A progressive continuous arm cranking test, modified for each group, was employed to elicit maximal responses with pulmonary and metabolic determinations made with open circuit spirometry and selected cardiovascular measurements made by impedance cardiography. Additionally, non-exercise static and dynamic lung function assessments were made. Quadriplegics had significantly lower $(p<0.05)$ tidal volumes, vital capacities, forced expiratory volumes at 1 seconds, and maximal breathing caapacities than the other two groups. The mean peak $\mathrm{VO}_{2}$ during maximal arm cranking was $28.2,25.3$ and $12.0 \mathrm{ml} / \mathrm{kg}$.min for the able-bodied $(A B)$, paraplegics $(P P)$ and quadriplegics $(Q P)$, respectively. Furthermore, reduced cardiovascular function was observed in the QP as evident in the low peak $H R(109 \mathrm{~b} / \mathrm{min})$, peak $S V(52 \mathrm{ml} / \mathrm{b})$ and peak $Q(5.7 \mathrm{l} / \mathrm{min})$. Values for the $Q P$ were $64^{\circ}{ }_{\circ}$ and $64^{\circ} \%$ peak $H R, 89^{\circ}{ }_{0}$ and $50^{\circ}{ }_{0}$ peak $S V$ and $54^{\circ}{ }_{0}$ and $33^{\circ}{ }_{0}$ peak $Q$ of values observed for the $P P$ and $A B$ groups, respectively. The peak $S V$ and $Q$ values were significantly lower $(P<0.05)$ for the PP group when compared with the AB group. Although not statistically significant the estimated $a-v \mathrm{O}_{2}$ difference was higher for both spinal cord injured groups ( 14.0 and $14.6 \mathrm{ml} \mathrm{O}_{2} / 100 \mathrm{ml}, P P$ and QP respectively). The impaired work capacity and reduced oxygen transport and utilisation of the QP group can be attributed to impaired sympathetic cardiac stimulation and a smaller available active muscle mass.

Key words: Paraplegics; Quadriplegics; Arm cranking; $\mathrm{VO}_{2}$ peak; Exercise; Stroke volume; Cardiac output. 


\section{Introduction}

The metabolic and circulatory responses to various modes of exercise have been studied extensively in able-bodied individuals. Investigators have examined the adaptability and limitations of both the central and peripheral circulatory systems to exercise modalities using different muscle groups (Astrand and Rodahl, 1977; Astrand and Saltin, 1961; Bevegard et al., 1966; Magel et al., 1978; Reybrouck et al., 1975; Stenberg, 1966 and Stenberg et al., 1967). Additionally, arm cranking has been used to assess physiological function in disabled individuals such as paraplegics and quadriplegics (Bevegard et al., 1966; Gass and Camp, 1984; Hjeltnes, 1977; Pollock et al., 1974; Wicks et al., 1977-78; Zwiren and Bar-Or, 1975). Available data, however, has been limited to acute and chronic effects of exercise on metabolic and ventilatory parameters. Few data are available on circulatory function, i.e. cardiac output, stroke volume and arteriovenous oxygen difference in spinal cord injured (SCI) individuals (Hjeltnes, 1977; Sawka et al., 1980). These studies reported similar circulatory function values for low level paraplegics when compared with able-bodied individuals while performing arm cranking exercise. Research evaluating the responses of the quadriplegic, primarily, has been restricted to measures of metabolic and ventilatory function during arm exercise. Virtually no information on functions such as cardiac output, stroke volume, and arteriovenous oxygen differences is available.

The purpose of this study was to characterise the metabolic and cardiovascular functions of quadriplegics and paraplegics during arm exercise and to compare these results with reference data of able-bodied individuals.

\section{Subjects and methods}

Thirty-two male and female subjects (11 able-bodied and 21 disabled) were recruited to participate in this study with written informed consent obtained from each individual. The subjects were divided into three groups according to their level of spinal cord injury: Group 1 Able-bodied $(A B, N=11)$ Group 2 Paraplegic with spinal cord lesion level T4-L3 (PP, N = 8), Group 3 Quadriplegic with spinal cord lesion level C5-C8 (QP, $N=13)$. Some of the subjects considered themselves to be wheelchair athletes and participated in activities such as basketball, archery and track. Each subject was required to make three visits to the laboratory. On the first visit each subject was given a formal orientation to the test procedures, consisting of familiarisation with the arm cranking instrument and accessories, i.e. mouthpiece, noseclip, the pulmonary function apparatus, and a neurological examination to determine the spinal lesion level. On the second visit the subject completed a 24-hour health and activity recall questionnaire and underwent both the pulmonary function tests and the maximal arm cranking test. The third visit was a replication of the pulmonary function and maximal arm cranking tests performed on the second visit (retest).

\section{Descriptive measurements}

Body weight and height were measured on each subject. Body weight was obtained on the disabled subjects by having the subject sit in a modified wheelchair on 
the scale the appropriate correction factor for the wheelchair was then subtracted from the total weight. All subjects were weighed while fully clothed but without shoes and/or orthopaedic braces. Weight was recorded to the nearest 100 grams. Height was measured, for the disabled subjects, while in an extended supine position on an examination table using a metal tape measure. For the able-bodied, height was taken while standing erect with their back against a stadiometer. Height was read and recorded to the nearest millimetre.

A 10-litre Collins spirometer, with motorised kymograph, was used to measure tidal volume (TV), forced vital capacity (FVC), forced expiratory volume in one second $\left(\mathrm{FEV}_{1 \cdot 0}\right)$, from which $\mathrm{FEV} / \mathrm{FVC}$ was calculated, and maximum breathing capacity (MBC). Spirometry measurements were performed in the sitting position for all subjects.

\section{Cardiovascular measurements}

Cardiac stroke volume was assessed using a non-invasive system, the IFM/Minnesota Impedance Cardiograph (Kubicek et al., 1966; Miller and Horvath, 1978). Procedurally, four strip electrodes (Electronic for Medicine, Greenwich, CT) were attached to the subject. A constant high frequency, sinusoidal, alternating current (I) was passed through the thorax between the two outer most electrodes ( 1 and 4$)$. The product of this current (I), multiplied by the thoracic impedance $(Z)$ measured between the two inner most electrodes ( 2 and 3 ), generated a voltage $(E)$ of $E=I \times Z$. This voltage was then measured by a high input linear impedance amplifier. The outputs were as follows: (1) $Z=$ impedance between electrodes 2 and 3 (ohms); (2) SV = stroke volume (ml); (3) $\mathrm{L}=$ the distance between electrodes 2 and $3(\mathrm{~cm}) ;(4) \mathrm{p}=$ resistivity of blood as a function of hematocrit $\left(53.2^{0.022} \mathrm{HCT}\right) ;(5) \mathrm{dZ} / \mathrm{dT}=$ rate of change of the impedance tracing (ohms/sec.); (6) $\mathrm{T}=$ ventricular ejection time (sec.). Hematocrit was determined for each subject. Stroke volume was calculated from the following formula:

$$
\mathrm{SV}(\mathrm{ml})=\mathrm{p} \times(\mathrm{L} / \mathrm{Z})^{2} \times \mathrm{dZ} / \mathrm{dT} \times \mathrm{T}
$$

Heart rate $(\mathrm{b} / \mathrm{min})$ was measured electrocardiographically. The electrocardiogram was recorded during the last 15 seconds of each workload. Additionally, arteriovenous oxygen difference $\left(\mathrm{a}-\mathrm{v} \mathrm{O}_{2}\right)$ was calculated by dividing peak oxygen consumption by cardiac output $\left(\mathrm{V}_{2} / \mathrm{Q}\right)$.

\section{Metabolic measurements}

Oxygen consumption $\left(\mathrm{VO}_{2}\right.$ stpd, $\left.1 / \mathrm{min}\right)$, carbon dioxide production $\left(\mathrm{VCO}_{2}\right.$, $1 / \mathrm{min})$, pulmonary ventilation $\left(\mathrm{V}_{\mathrm{E}}\right.$ btps, $\left.1 / \mathrm{min}\right), \mathrm{O}_{2}$ pulse and respiratory exchange ratio $(R)$ were obtained by open circuit spirometry while subjects breathed through a two-way respiratory valve (Collins). One minute aliquots of expired gas were collected in metallised polyethylene bags (Johnson et al., 1967) and analysed for oxygen and carbon dioxide. Gas analysers were calibrated with references gases of known concentration, previously determined by the microScholander technique. Minute volumes of expired gases were measured by a dry gasometer (Parkinson-Cowan CD-4) that was previously calibrated against a 120-litre Tissot gasometer. 
Table I Physical characteristics and pulmonary function of able-bodied, paraplegic and quadriplegic subjects

\begin{tabular}{|c|c|c|c|c|c|c|c|c|c|c|}
\hline Group & $\mathrm{N}$ & $\begin{array}{l}\text { Age } \\
\text { yrs }\end{array}$ & $\begin{array}{c}\text { Lesion } \\
\text { level }\end{array}$ & $\begin{array}{l}\mathrm{HT} \\
\mathrm{cm}\end{array}$ & $\begin{array}{l}\text { WT } \\
\mathrm{kg}\end{array}$ & $\begin{array}{c}\text { TV } \\
1\end{array}$ & $\begin{array}{c}\text { FVC } \\
1 \\
\end{array}$ & $\begin{array}{c}\mathrm{FEV}_{1.0} \\
1\end{array}$ & $\begin{array}{c}\text { FEV/FVC } \\
0 \\
0\end{array}$ & $\begin{array}{l}\text { MBC } \\
1 / \mathrm{min}\end{array}$ \\
\hline Able-bodied & 11 & $\begin{array}{r}26 \cdot 2 \\
\pm 1 \cdot 2\end{array}$ & - & $\begin{array}{r}176.3 \\
\pm 3.6\end{array}$ & $\begin{array}{r}71 \cdot 2 \\
\pm 4.6\end{array}$ & 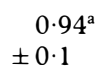 & $\begin{aligned} & 5 \cdot 5^{\mathrm{a}} \\
\pm & 0 \cdot 4\end{aligned}$ & $\begin{aligned} & 4 \cdot 5^{\mathrm{a}} \\
\pm & 0 \cdot 3\end{aligned}$ & $\begin{array}{r}81 \\
\pm 2\end{array}$ & $\begin{array}{c}152 \cdot 1^{\mathrm{a}} \\
\pm 12 \cdot 7\end{array}$ \\
\hline Paraplegic & 8 & $\begin{array}{r}25 \cdot 2 \\
\pm 2 \cdot 9\end{array}$ & T4-L3 & $\begin{array}{r}170 \cdot 3 \\
\pm 3 \cdot 7\end{array}$ & $\begin{array}{r}60 \cdot 2 \\
\pm 2 \cdot 8\end{array}$ & $\begin{array}{ll} & 0 \cdot 86^{\mathrm{a}} \\
\pm & 0 \cdot 2\end{array}$ & $\begin{array}{r}4 \cdot 6^{\mathrm{a}} \\
\pm 0 \cdot 4\end{array}$ & $\begin{aligned} & 3 \cdot 8^{\mathrm{a}} \\
\pm & 0 \cdot 3\end{aligned}$ & $\begin{array}{r}84 \\
\pm 3\end{array}$ & $\begin{array}{c}133 \cdot 8^{\mathrm{a}} \\
\pm 11 \cdot 1\end{array}$ \\
\hline Quadriplegic & 13 & $\begin{array}{r}29.6 \\
\pm 2.5\end{array}$ & $\mathrm{C} 5-\mathrm{C} 8$ & $\begin{array}{l}176 \cdot 0 \\
\pm 2 \cdot 3\end{array}$ & $\begin{array}{r}62 \cdot 2 \\
3 \cdot 4\end{array}$ & $\begin{array}{ll} & 0 \cdot 64^{\mathrm{b}} \\
\pm & 0 \cdot 1\end{array}$ & $\begin{aligned} & 3 \cdot 1^{\mathrm{b}} \\
\pm & 0 \cdot 2\end{aligned}$ & $\begin{aligned} & 2 \cdot 7^{\mathrm{b}} \\
\pm & 0 \cdot 1\end{aligned}$ & $\begin{array}{r}85 \\
\pm 3\end{array}$ & $\begin{array}{c}94 \cdot 3^{b} \\
6 \cdot 3\end{array}$ \\
\hline
\end{tabular}

Values are means \pm Standard deviations; different superscripts indicate significant differences $(\mathrm{p}<0.05)$.

Table II Metabolic parameters of able-bodied, paraplegic and quadriplegic subjects to maximal effort arm cranking exercise

\begin{tabular}{lccccccc}
\hline Group & $\mathrm{N}$ & $\begin{array}{c}\text { Workload } \\
\mathrm{Kpm} / \mathrm{min}\end{array}$ & $\begin{array}{c}\mathrm{VO}_{2} \\
1 / \mathrm{min}\end{array}$ & $\begin{array}{c}\mathrm{VO}_{2} \\
\mathrm{ml} / \mathrm{Kg} \mathrm{min}\end{array}$ & $\begin{array}{c}\mathrm{VCO}_{2} \\
1 / \mathrm{min}\end{array}$ & $\mathrm{R}$ & $\begin{array}{c}\mathrm{O}_{2} \text { Pulse } \\
\mathrm{ml} / \mathrm{b}\end{array}$ \\
\hline Able-bodied & 11 & 584 & $2 \cdot 1^{\mathrm{a}}$ & $28 \cdot 2^{\mathrm{a}}$ & $2 \cdot 4^{\mathrm{a}}$ & $1 \cdot 15^{\mathrm{a}}$ & $12 \cdot 7^{\mathrm{a}}$ \\
& & \pm 67 & $\pm 0 \cdot 9$ & $\pm 6 \cdot 8$ & $\pm 1 \cdot 0$ & $\pm 0 \cdot 07$ & $\pm 5 \cdot 4$ \\
Paraplegic & 8 & 522 & $1 \cdot 5^{\mathrm{b}}$ & $25 \cdot 3^{\mathrm{a}}$ & $1 \cdot 7^{\mathrm{b}}$ & $1 \cdot 14^{\mathrm{a}}$ & $9 \cdot 7^{\mathrm{ab}}$ \\
& & \pm 80 & $\pm 0 \cdot 6$ & $\pm 7 \cdot 4$ & $\pm 0 \cdot 8$ & $\pm 0 \cdot 22$ & $\pm 4 \cdot 2$ \\
Quadriplegic & 13 & 141 & $0 \cdot 8^{\mathrm{c}}$ & $12 \cdot 0^{\mathrm{b}}$ & $0 \cdot 7^{\mathrm{c}}$ & $0 \cdot 92^{\mathrm{b}}$ & $7 \cdot 5^{\mathrm{bc}}$ \\
& & \pm 18 & $\pm 0 \cdot 2$ & $\pm 3 \cdot 3$ & $\pm 0 \cdot 3$ & \pm 0.16 & $\pm 2 \cdot 0$ \\
\hline
\end{tabular}

Values are means \pm standard deviations; different superscripts indicate significant differences $(\mathrm{p}<0.05)$.

\section{Test protocol}

Arm cranking was performed on a modified Monarch bicycle ergometer. The arm crank unit was inserted into the seat support of the Monarch and secured by two bolts. A chain and sprocket coupled the arm crank to the flywheel of the Monarch maintaining standard gearing of the bicycle such that one arm crank revolution resulted in the flywheel travelling a distance of 6 metres. A speedometer was observed by the subject to maintain the required velocity. In addition, an electronic metronome was used to aid the subject in cranking at the prescribed speed $(50 \mathrm{rpm})$. An adjustable chair was mounted in a hydraulic lift so that the subject could be positioned with the shoulders level and in-line with the arm crank. Each subject performed a progressive, continuous arm-cranking test including a 2 minute warm-up bout and 2 minute progressive exercise bouts until volitional exhaustion. The starting workload for the quadriplegics (QP) was set at $75 \mathrm{kpm} / \mathrm{min}$ with increments of $75 \mathrm{kpm} / \mathrm{min}$ every 2 minutes. The workload for the paraplegics (PP) and able-bodied (AB) subjects was set at $150 \mathrm{kpm} / \mathrm{min}$ with increases of $150 \mathrm{kpm} / \mathrm{min}$ every 2 minutes. Testing was terminated at the subject's volitional point of exhaustion.

Statistical analyses included descriptive statistics and analysis of variance to test the significance of differences between groups. The 0.05 level of significance was used to determine significant differences. 


\section{Results}

The physical characteristics and pulmonary function data for the three groups are presented in Table I. Analysis of the pulmonary data indicated that the quadriplegics had significantly lower values than did the able-bodied and paraplegic subjects for all variables except FEV/FVC.

Values for metabolic parameters recorded during the minute of exercise when peak oxygen consumption was achieved are shown in Table II. The analysis between groups showed significant differences between all three groups for $\mathrm{VO}_{2}$ and $\mathrm{VCO}_{2}(1 / \mathrm{min})$. Significantly lower values were observed for the QP group compared to the $\mathrm{PP}$ and $\mathrm{AB}$ groups for $\mathrm{VO}_{2}$ when expressed relative to body weight $(\mathrm{ml} / \mathrm{kg} / \mathrm{min})$. The difference between the three groups appears to be related to spinal lesion level (Fig.). The data plotted in this figure demonstrate that lower values were obtained on the $\mathrm{QP}$ subjects compared to the $\mathrm{PP}$ and $\mathrm{AB}$ subjects. Likewise, the similarities in $\mathrm{VO}_{2} \mathrm{ml} / \mathrm{kg} / \mathrm{min}$ for the $\mathrm{PP}$ and $\mathrm{AB}$ groups are illustrated. The $\mathrm{O}_{2}$ pulse $(\mathrm{ml} / \mathrm{b})$ values for the QP group were similar to those of the PP group but significantly lower than those obtained on the AB group. The QP subjects also had significantly lower values for respiratory exchange ratio $(\mathrm{R})$ compared to the other two groups.

Pulmonary and ventilatory responses to the arm cranking exercise are displayed in Table III. The QP group again demonstrated significantly lower values than the other two groups for pulmonary ventilation $\left(V_{E}\right.$ btps $\left.1 / \mathrm{min}\right)$ and tidal volume (1). There was no difference between groups for respiratory rate and ventilatory equivalent $\left(1 / 100 \mathrm{ml} \mathrm{O}_{2}\right)$.

The peak cardiovascular responses to the arm cranking exercise are shown in Table IV. The QP group had significantly lower values for all parameters, except a-v $\mathrm{O}_{2}$ difference, when compared to the PP and $\mathrm{AB}$ groups. In addition, the PP subjects had significantly lower values for stroke volume $(\mathrm{ml} / \mathrm{b})$, cardiac output

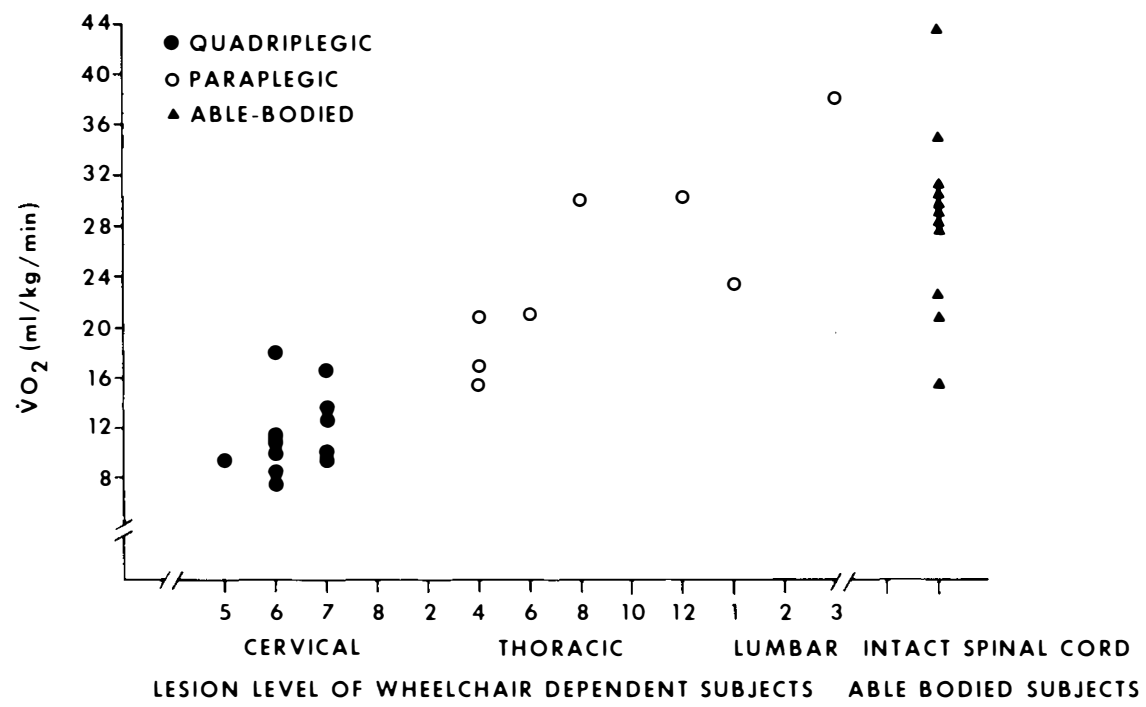

Figure Relationship between spinal cord injury and peak oxygen consumption during arm cranking exercise. 
Table III Pulmonary and ventilatory responses of able-bodied, paraplegic and quadriplegic subjects to maximal effort arm cranking exercise

\begin{tabular}{|c|c|c|c|c|c|}
\hline Group & $\mathrm{N}$ & $\begin{array}{c}\mathrm{V}_{\mathrm{E}}(\mathrm{BTPS}) \\
(\mathrm{l} / \mathrm{min})\end{array}$ & $\begin{array}{c}\text { Respiratory } \\
\text { rate } \\
\text { (br min) }\end{array}$ & $\begin{array}{c}\mathrm{VE} / \mathrm{VO}_{2} \\
1 / 100 \mathrm{ml} \mathrm{O}_{2}\end{array}$ & $\begin{array}{c}\text { Tidal volume } \\
\text { (1) }\end{array}$ \\
\hline Able-bodied & 11 & $\begin{array}{r}84 \cdot 3^{\mathrm{a}} \\
\pm 36 \cdot 9\end{array}$ & $\begin{array}{l}40^{\mathrm{a}} \\
\pm 9\end{array}$ & $\begin{array}{r}3 \cdot 5^{\mathrm{a}} \\
\pm \\
0.6\end{array}$ & $\begin{aligned} & 1.9^{\mathrm{a}} \\
\pm & 0.7\end{aligned}$ \\
\hline Paraplegic & 8 & $\begin{array}{r}68 \cdot 7^{\mathrm{a}} \\
\pm 32 \cdot 7^{2}\end{array}$ & $\begin{array}{l}42^{\mathrm{a}} \\
\pm 7\end{array}$ & $\begin{array}{r}4 \cdot 0^{\mathrm{a}} \\
\pm 0 \cdot 7\end{array}$ & $\begin{array}{l}1 \cdot 4^{\mathrm{a}} \\
\pm 0.5\end{array}$ \\
\hline Quadriplegic & 13 & $\begin{array}{l}26 \cdot 6^{\mathrm{b}} \\
\pm 8 \cdot 3\end{array}$ & $\begin{array}{l}33^{\mathrm{a}} \\
\pm 7\end{array}$ & $\begin{aligned} & 3 \cdot 3^{\mathrm{a}} \\
\pm & 0 \cdot 7\end{aligned}$ & $\begin{array}{c}0 \cdot 8^{\mathrm{b}} \\
\pm 0 \cdot 2\end{array}$ \\
\hline
\end{tabular}

Values are means \pm standard deviations; different superscripts indicate significant differences $(\mathrm{p}<0.05)$.

Table IV Cardiovascular responses of able-bodied, paraplegic, and quadriplegic subjects to maximal effort and cranking exercise

\begin{tabular}{|c|c|c|c|c|c|c|}
\hline Group & $\mathrm{N}$ & $\begin{array}{c}\mathrm{HR} \\
\mathrm{b} \min \end{array}$ & $\begin{array}{c}\mathrm{SV} \\
\mathrm{ml} \mathrm{b}\end{array}$ & $\begin{array}{l}\mathrm{Q} \\
\mathrm{l} / \mathrm{min}\end{array}$ & $\begin{array}{c}Q \text { index } \\
1 / \mathrm{m}^{2}\end{array}$ & $\begin{array}{c}\mathrm{A}-\mathrm{V} \mathrm{O} \mathrm{O}_{2} \\
\text { diff }\end{array}$ \\
\hline \multirow[t]{2}{*}{ Able-bodied } & 11 & $168^{\mathrm{a}}$ & $104 \cdot 3^{a}$ & $17 \cdot 2^{\mathrm{a}}$ & $9 \cdot 2^{\mathrm{a}}$ & $12 \cdot 8^{\mathrm{a}}$ \\
\hline & & \pm 14 & \pm 23.8 & $\pm 3 \cdot 2$ & $\pm 2 \cdot 0$ & $\pm 4 \cdot 5$ \\
\hline \multirow[t]{2}{*}{ Paraplegic } & 8 & $160^{\mathrm{a}}$ & $58 \cdot 4^{\mathrm{b}}$ & $10 \cdot 5^{\mathrm{b}}$ & $5 \cdot 9^{\mathrm{b}}$ & $14 \cdot 6^{\mathrm{a}}$ \\
\hline & & \pm 32 & $\pm 35 \cdot 4$ & $\pm 5 \cdot 6$ & $\pm 3 \cdot 0$ & $\pm 2 \cdot 8$ \\
\hline \multirow[t]{2}{*}{ Quadriplegic } & 13 & $109^{\mathrm{b}}$ & $52 \cdot 0^{c}$ & $5 \cdot 7^{\mathrm{c}}$ & $3 \cdot 23^{c}$ & $14 \cdot 0^{\mathrm{a}}$ \\
\hline & & \pm 17 & $\pm 8 \cdot 6$ & $\pm 1 \cdot 3$ & $\pm 0 \cdot 8$ & $\pm 5 \cdot 0$ \\
\hline
\end{tabular}

Values are means \pm standard deviations; different superscripts indicate significant differences $(\mathrm{p}<0.05)$.

$(1 / \mathrm{min})$, and cardiac index $\left(1 / \mathrm{m}^{2} \mathrm{BSA}\right)$ when compared with the $\mathrm{AB}$ subjects. Although statistically insignificant, the QP and PP groups demonstrated slightly higher values for a-v $\mathrm{O}_{2}$ difference when compared to the $\mathrm{AB}$ group.

\section{Discussion}

The results of the present study reflect the physiological characteristics of men and women from three different neurologial classificiations: able-bodied, paraplegics and quadriplegics. The pulmonary function results for the able-bodied subjects are similar to those reported by Zwiren and Bar-Or (1975). The values for the paraplegics, in the present study, were in the range of values reported by Hjeltnes (11977) and Zwiren and Bar-Or for both sedentary and active wheelchair dependent individuals. In contrast, the paraplegic values for FVC, $\mathrm{FEV}_{1 \cdot 0}$ and FEV/FVC were below those values of Gass and Camp (1984) for highly trained wheelchair athletes. These differences in pulmonary function, in the present study, and those reported by other investigators (Gass and Camp, 1979; Glaser et al., 1980; Sawka et al., 1980) may be attributed to grouping all of the paraplegics, i.e. men and women, active and sedentary, into one group and/or not separating the PP group into high and low lesion levels.

Reseach in the area of central circulatory responses to exercise with differing amounts of muscle mass, e.g. arms vs. legs, has suggested that an increase in muscle mass results in a larger oxygen consumption, higher ventilation, larger 
$\mathrm{O}_{2}$ pulse, larger cardiac output and an increased maximal heart rate (Astrand and Rodahl, 1977; Astrand et al., 1964; Astrand and Saltin, 1961; Bevegard et al., 1966; Magel et al., 1978; Reybrouck et al., 1975; Rowell, 1974 and Stenberg et al., 1967). It would, therefore, be reasonable to expect higher physical work capacities in subjects with a larger functional muscle mass. The work of Coutts et al. (1983) demonstrated significant differences in $\mathrm{VO}_{2}(1 / \mathrm{min})$ between quadripegics, high level paraplegics and low level paraplegics.

Additionally, significantly lower heart rates were observed for the quadriplegics compared with both the high and low level paraplegics. Similarly, Gass and Camp (1979) reported significantly lower values for $\mathrm{VO}_{2}(1 / \mathrm{min})$ between quadriplegics and high and low level paraplegics as well as a lower maximal heart rate for the quadriplegic subjects compared to all of the other paraplegic subjects. In the present study, all three groups demonstrated significantly different values for peak oxygen consumption $(1 / \mathrm{min})$, with the $A B$ subjects achieving the highest values and the PP and QP subjects obtaining lower values.

The peak $\mathrm{VO}_{2}(1 / \mathrm{min})$ values for the paraplegics were lower than those reported by Gass and Camp (1979) and Glaser et al. (1980), within the range of values reported by Hjeltnes (1977) and Zwiren and Bar-Or (1975) but higher than those reported by Wicks et al. (1977-78). The peak $\mathrm{VO}_{2}$ values achieved by the QP, in the present study, are lower than those reported by Coutts et al. (1983), Gass and Camp (1979) and Wicks et al. (1977-78).

The maximal heart rate recorded by Coutts et al., Gass and Camp and Wicks et al., indicated a significantly lower heart rate for the quadriplegics compared with the paraplegics during arm exercise. Similarly, significantly lower maximal heart rates were observed for the QP compared to the PP and AB subjects in the present study. This lower heart rate for the quadriplegic subjects may be attributed to a reduced sympathetic stimulation (neuronal and circulating catecholamines) as well as other possible factors (neurogenic, humoral, temperature, etc.) resulting from a lower metabolic rate and smaller active skeletal muscle mass. More research in this area is necessary before a conclusion can be drawn.

Central and peripheral circulatory function, as measured by stroke volume $(\mathrm{ml} / \mathrm{b})$, cardiac output $(\mathrm{l} / \mathrm{min})$, and a-v $\mathrm{O}_{2}$ difference $(\mathrm{ml} / 100 \mathrm{ml})$, have been reported previously for paraplegics (Hjeltnes, 1977) but not for quadriplegic individuals. The results for the able-bodied individuals in this study can be compared with the work of Astrand et al. (1964), Astrand and Saltin (1961), Bevegard et al. (1966) and Stenberg et al. (1967). The values for the able-bodied individuals are within the range of values reported by these other investigators for arm exercise, i.e. approximately $75^{\circ}{ }^{\circ}$, of maximal leg exercise values. However, the values for cardiac stroke volume and cardiac output for the paraplegics and quadriplegics were significantly lower than those of the able-bodied subjects. The cardiac output of the PP in the present study are within the range of values reported by Hjeltnes (1977), i.e. 5 to $15 \mathrm{l} / \mathrm{min}$. Similarly, the stroke volume for the paraplegics, in this study, are in agreement with the values reported by Hjeltnes (1977; Table IV).

Furthermore, the QP demonstrated values for stroke volume and cardiac output that were lower than those obtained by the PP group. The lower stroke volumes recorded for both wheelchair dependent groups may be related to a 
decreased venous return to the heart as a consequence of a reduced active muscle pump in the lower limbs. In the case of the PP, the decreased cardiac input does not appear to be the result of a decreased heart rate since the heart rate for the PP group was similar $(160 \mathrm{~b} / \mathrm{min})$ to the AB group $(168 \mathrm{~b} / \mathrm{min})$. Although the exercise mode consisted of arm cranking, the able-bodied subjects were capable of movement in the lower torso as well as secondary muscular contractions in the lower limbs as the workload was increased. These secondary muscle contractions may aid the venous return to the heart and thus assist in maintaining the stroke volume and cardiac output. This would be expected during arm exercise when an active muscle pump from the lower extremities has been limited.

In contrast, the lower cardiac output of the QP subjects resulted from a combination of a lower stroke volume and a lower heart rate during exercise. Interestingly, the three groups showed no significant differences in their a-v $\mathrm{O}_{2}$ difference. Unlike the results reported by Hjeltnes (1977) for paraplegics, the values reported in this study are similar to those reported for able-bodied individuals during arm exercise, i.e. approximately $70^{\circ}{ }_{0}$ of the theoretical maximal value. These values for the a-v $\mathrm{O}_{2}$ differences are indicative of normal oxygen extraction in the periphery, suggesting that the regional blood flow to the working muscles was normal.

In conclusion, the present investigation found that in a mixed sample (males and females) of able-bodied and wheelchair dependent individuals significantly lower values for tidal volume (1), forced vital capacity (1), $\mathrm{FEV}_{1 \cdot 0}$ and $\mathrm{MBC}$ $(1 / \mathrm{min})$ were observed for quadriplegic subjects compared with paraplegic and able-bodied subjects. Furthermore, significantly lower values for $\mathrm{VO}_{2}(1 / \mathrm{min})$, $\mathrm{VO}_{2}(\mathrm{ml} / \mathrm{kg} / \mathrm{min}), \mathrm{VCO}_{2}(1 / \mathrm{min}), \mathrm{O}_{2}$ pulse $(\mathrm{ml} / \mathrm{b})$, stroke volume $(\mathrm{ml} / \mathrm{b})$, cardiac output $(1 / \mathrm{min})$, and cardiac index $\left(1 / \mathrm{m}^{2} \mathrm{BSA}\right)$ were obtained for both the PP and QP groups compared to the observed values for the AB group. These differences may be attributed to a reduction of active muscle mass and/or impaired sympathetic innervation resulting in a lack of cardiac acceleration during exercise, and may have been responsible for hypokinetic circulation, which diminishes circulatory pressure, resulting in a reduced venous return. Further research is needed for a better understanding of these complex mechanisms.

\section{Acknowledgements}

This project was made possible by a grant from the Technology and Research Foundation of the Paralyzed Veterans of America. Support also was provided by the Division of Rehabilitation and Education and the Department of Physical Education, University of Illinois, Urbana-Champaign, IL., U.S.A.

\section{References}

Astrand PO, Rodahl K 1977 Textbook of work physiology: Physiological bases of exercise. McGraw-Hill Book Co., New York

Astrand PO, Cuddy TE, SAltin B, et al. 1964 Cardiac output during submaximal and maximal work. Fournal of Applied Physiology 19:268-274

Astrand PO, SALTIN B 1961 Maximal oxygen uptake and heart rate in various types of muscular activity. Fournal of Applied Physiology 16(6):977-981

BAR-OR O, SPIRA R 1976 Physiological efects of a sports rehabilitation program on cerebral palsied and postpoliomyelitic adolescents. Medicine and Science in Sports and Exercise $8(3)$ : 157-161 
Bevegard S, Freyschuss U, Strandell T 1966 Circulatory adaptation to arm and leg exercise in supine and sitting position. Fournal of Applied Physiology 21(1):37-46

BRATTGARD S-O, GRIMBY G, Hook O 1970 Energy expenditure and heart rate in driving a wheelchair ergometer. Scandinavian fournal of Rehabilitation Medicine 2:143-148

Coutts KD, RhODEs EC, MCKenZIE DC 1983 Maximal exercise responses of tetraplegics and paraplegics. Fournal of Applied Physiology 55(2):479-482

GASS GC, CAMP EM 1969 Physiological characteristics of trained Australian paraplegic and tetraplegic subjects. Medicine and Science in Sports and Exercise 11(3):256-259

GASS GC, CAMP EM 1984 The maximal physiological responses during incremental wheelchair and arm cranking exercise in male paraplegics. Medicine and Science in Sports and Exercise 16(4):355-359

Glaser RM, SAWKa MN, BRUNE MF, et al. 1980 Physiological responses to maximal effort wheelchair and arm crank ergometry. Fournal of Applied Physiology 48(6):1060-1064

HJEL TNES N 1977 Oxygen uptake and cardiac output in graded arm exercise in paraplegics with low spinal lesions. Scandinavian fournal of Rehabilitation Medicine 9:107-113

Johnson RE, Robbins F, SCHILkE R, et al. 1967 A versatile system for measuring oxygen consumption in man. Fournal of Applied Physiology 22:377-379

Kubicek WG, Karnegis JN, Patterson RP, et al. 1966 Development and evaluation of an impedance cardiac output system. Aerospace Medicine 37:1208-1212

MAGEL JR, MCARDLE WD, TONER M, et al. 1978 Metabolic and cardiovascular adjustment to arm training. Fournal of Applied Physiology 45(1):75-79

Miller JC, HoRvath SM 1978 Methodology: Impedance cardiography. Psychophysiology 15(1): 80-91

Pollock ML, Miller HS, Linnerud AC, et al. 1974 Arm pedalling as an endurance training regimen for the disabled. Archives of Physical Medicine and Rehabilitation 55:418-424

REYBROUCK T, HEIGENHAUSER GF, FAULKNER JA 1975 Limitation to maximum oxygen uptake in arm, leg, and combined arm-leg ergometry. Fournal of Applied Physiology 38(5):774-779

Rhodes EC, MCKenZIE DC, CoutTs KD, et al. 1981 A field test for the prediction of aerobic capacity in male paraplegics and quadriplegics. Canadian fournal of Applied Sport Sciences 6(4): $182-186$

RoweLl LB 1974 Human cardiovascular adjustments to exercise and thermal stress. Physiological Reviews 54(1):75-159

SAWKa MN, GLASER RM, WILDE SW, et al. 1980 Metabolic and circulatory responses to wheelchair and arm crank exercise. Fournal of Applied Physiology 49(5):784-788

STENBERG J 1966 The significance of central circulation for the aerobic work capacity under various conditions in young healthy persons. Acta Physiologica Scandinavica 68(Suppl.273):1-26

Stenberg J, Astrand P-O, Ekblom B, et al. 1967 Hemodynamic responses to work with different muscle groups sitting and supine. Fournal of Applied Physiology 22:61-70

WICKS JR, LyMBURNER K, DinSDALE SM, et al. 1977-78 The use of multistage exercise testing with wheel-chair ergometry and arm cranking in subjects with spinal cord lesions. Paraplegia 15:252-261

ZWIREN LD, BAR-OR O 1975 Response to exercise of paraplegics who differ in conditioning level. Medicine and Science in Sports and Exercise 7(2):94-98 